\title{
Tribunal Superior de Justicia de Andalucía
}

\section{ACTO ADMINISTRATIVO.}

Revocación de licencia de armas a procesado por delito de violencia de género. Improcedencia. Discrecionalidad administrativa en el otorgamiento y revocación de estas licencias.

Se interpone el presente recurso contencioso-administrativo el 21 de mayo de 2014 contra la resolución de 14 de marzo de 2014 dictada por la Subdelegación del Gobierno en Granada que desestimó el recurso de reposición deducido el 16 de enero de 2014 contra la resolución de 26 de diciembre de 2013 del Subdelegado del Gobierno en Granada dictada en el expediente NUM000, que revocó la licencia de armas tipo E.

La parte recurrente aduce que los hechos en forma de antecedentes que ha ponderado la Administración para tomar el acuerdo ahora impugnado no ponen de manifiesto una conducta reveladora de un potencial riesgo para terceras personas que puedan derivarse del mantenimiento de la autorización al recurrente para usar armas de caza y que puedan justificar su revocación.

Los datos que barajó la Administración para el inicio del expediente de revocación de la licencia de armas y que concluyó con la resolución que así lo acordaba, fueron los que contenía el informe emitido por el Teniente Interventor de Armas de la Guardia Civil el 13 de diciembre de 2013. La resolución del Subdelegado objeto de la presente litis en los hechos que consigna reseñaba el informe de la Unidad de Violencia sobre la Mujer de 8 de octubre de 2013 recoge que" la ex pareja declara que venía sufriendo malos tratos psicológicos, vejaciones y amenazas durante el comienzo de la relación hace 18 años...(...) También destacó que su ex pareja prestó especial atención en buscar y llevarse las cartuchos de las escopetas las cuales se las había llevado previamente cuando vino en febrero- es decir 10 meses antes de ese informe-".

1 Subsección preparada por JOSÉ LUIS RIVERO YSERN. Catedrático de Derecho Administrativo, Univesidad de Sevilla. 
La parte recurrente esgrime que el Juzgado de Primera Instancia e Instrucción número dos de Santa Fé en las Diligencias Urgentes de Juicio Rápido número 61/2013, dictó auto de sobreseimiento provisional y su archivo porque no existían elementos suficientes para acordar la apertura del Juicio oral contra el acusado imputado como autor de un delito de malos tratos del artículo- sic-1563 del Código Penal. Esa resolución la dicta, según expone, porque la declaración de una testigo que presenció los hechos puso de manifiesto al Juzgador que las lesiones que pudiera presentar la denunciante derivarían de un golpe fortuito cuando ambos, la denunciante y el denunciado, fueron a coger al mismo tiempo las llaves. Ello hizo que se declarara el sobreseimiento provisional, el archivo de las actuaciones y que no hubiera lugar a la adopción de las medidas cautelares de alejamiento o protección. Así mismo el Ministerio Fiscal no se opuso a que las armas requisadas al ahora recurrente se devolvieran, lo que se acordó el 8 de octubre de 2013 mediante oficio dirigido a la Intervención de Armas de la Guardia Civil. Igualmente la parte recurrente asevera que esas armas se vendieron, sin que haya aportado documento que acredite esa transmisión.

Quedaría incompleta la anterior reseña fáctica si no añadiéramos que con posterioridad al dictado de la resolución ahora cuestionada, a raíz de las Diligencias Previas número 251/2014, el 26 de mayo de 2016 el Juzgado de Primera Instancia e Instrucción número Tres de Santa Fé dictó auto elevando a aquellas a Procedimiento Abreviado número 42/2014, por un delito de acusación y denuncia falsa del artículo 456 bis del Código Penal contra doña Miriam por la denuncia que en su día formuló contra el ahora recurrente y que concluyó con el auto de sobreseimiento ya referido.

Expuesto el objeto de la controversia en el fundamento anterior, hemos de tener en cuenta, como con reiteración viene declarando el Tribunal Supremo, que el acto administrativo de concesión o denegación de la licencia de armas, y en su caso la revocación, se encuadra dentro de lo que constituye el ejercicio de una potestad discrecional, pero que no puede convertirse en arbitrariedad, al estar ésta rechazada por el artículo 9.3 de la Constitución - Por ello, la concesión o denegación, al igual que la revocación, ha de basarse en la consideración de las circunstancias concurrentes en el caso concreto, a fin de valorar si los solicitantes de licencia o permiso de armas (o aquellos respecto de los cuales se pretende su revocación) reúnen, conforme a lo previsto en el Reglamento de Armas (aprobado por R.D. 137/1993, de 29 de enero), las aptitudes psicofísicas adecuadas y los conocimientos necesarios en orden a la conservación, mantenimiento y manejo de las armas, de tal modo que su posesión no constituya razón de peligro para sí ni 
para terceras personas (sentencia de 5 de febrero de 1996). Según la misma doctrina, habrán de examinarse los informes de conducta y antecedentes del solicitante para valorar la concesión o denegación.

Igualmente, el Tribunal Supremo, en diversas sentencias (entre las que podemos citar las de 14 de noviembre de 1984,21 de junio de 1985,17 de enero y 8 marzo de 1986, así como la de 4 de junio de 1998), ha afirmado que en los supuestos de autorización, renovación o revocación de permisos de armas, nos encontramos ante supuestos de "autorización", en los que la valoración de las circunstancias, hechos o datos concurrentes, exige, por razón del interés general, una atribución de facultad discrecional a favor de la autoridad concedente y que no puede ser desconocida en ningún caso, sin que ello suponga una atribución de poder arbitrario. $\mathrm{Y}$ en este sentido es posible que el juicio de la autoridad gubernativa incida en error por no apreciar de forma correcta los hechos determinantes o dar por existentes ciertos hechos negativos que no merezcan tal calificación a los efectos de denegar la autorización solicitada o su revocación.

En definitiva, podemos establecer como principios generales sobre la concesión de la licencia de armas, a la luz de la doctrina jurisprudencial expuesta, los siguientes:

a) Que no existe un derecho incondicional a la obtención de la licencia, debiendo prevalecer un criterio restrictivo siguiendo la orientación de la Ley Orgánica sobre Protección de la Seguridad Ciudadana.

b) Que la concesión de la licencia no es un acto reglado, sino discrecional, que no admite la arbitrariedad administrativa, siendo susceptible de control jurisdiccional.

c) Que prima el interés general manifestado en la seguridad sobre el interés privado, procediendo la denegación si existe un posible riesgo propio o ajeno.

d) Que es preciso analizar todas las circunstancias que rodean al caso concreto, para ver si de ellas existe o no o puede derivarse la peligrosidad del peticionario que justificaría o no la denegación de la licencia.

Resulta obligado recordar el carácter restrictivo de la concesión de permisos o licencias para la tenencia de armas de fuego. En efecto, ya el Tribunal Supremo en sentencia de 8 de abril de 2008 ( RJ 2008,1891), con cita de sentencias anteriores, destacaba ese nuevo carácter que rige esta materia debido al cambio normativo operado por la promulgación del nuevo Reglamento de Armas, aprobado por el Real Decreto 137/1993, de 29 de enero, en comparación con el antiguo Reglamento, aprobado 
por Real Decreto 2179/1981. Dijo en esa y en anteriores sentencias que "una cosa es que el procedimiento no haya cambiado y otra cosa es que haya identidad en los preceptos citados. No la hay. Porque claramente se advierte la introducción de un punto de rigor en la nueva reglamentación que no se limita a hablar de discrecionalidades sino que se añade... que la expedición de la licencia tendrá carácter restrictivo limitándose a supuestos de existencia de riesgo especial o de necesidad" Añadiéndose que "es claro, pues, que bajo la normativa anterior la libertad estimativa que contiene toda potestad discrecional ha sido reducida, pues el otorgamiento queda sujeto a un mandato imperativo muy preciso: la citada potestad de otorgamiento ha de ejercerse de manera restrictiva".

Así pues, la jurisprudencia ya ha declarado con reiteración, y en lo que aquí importa: 1) que no existe en nuestro Ordenamiento Jurídico un derecho a obtener licencias de armas, cuya expedición tiene carácter restrictivo; 2) que hay que realizar una valoración global de las circunstancias personales del solicitante.

En esa línea expositiva, debemos reseñar igualmente que tampoco la existencia del derecho a cazar a que se refiere el artículo 3 de la Ley 1/1970, de 4 de abril, desvirtúa las anteriores conclusiones, puesto que, como se desprende del apartado 4 de dicho precepto, la efectividad de aquel derecho requiere la previa obtención del correspondiente permiso, cuando se pretenda utilizar armas u otros medios que precisen de autorización especial.

Conforme a una reiterada jurisprudencia de la Sala de lo ContenciosoAdministrativo del Tribunal Supremo, de la que son exponente las sentencias de 28 de enero de 2008 ( RG 1059/2004), de 21 de mayo de 2009 ( RG 500/2005 ), y de 27 de noviembre de 2009 ( RC 6374/2005 ), el artículo 98.1 del Reglamento de Armas, que dispone que « En ningún caso podrán tener ni usar armas, ni ser titulares de las licencias o autorizaciones correspondientes, las personas cuyas condiciones psíquicas o físicas les impidan su utilización, y especialmente aquellas personas para las que la posesión y el uso de armas representen un riesgo propio o ajeno ", determina que el control administrativo que se describe en este precepto no sólo se extiende al momento de la concesión de la licencia o autorización, sino que también se proyecta sobre el mantenimiento de las mismas aptitudes o condiciones exigibles para ser titular de la licencia concedida, de manera que cuando, una vez concedida la autorización, la Administración tiene conocimiento de nuevas circunstancias, que han alterado las condiciones originarias concurrentes al tiempo del otorgamiento, o han determinado 
su desaparición, debe valorar este nuevo estado de cosas y motivar sobre la necesidad de su revocación.

Por tanto, un correcto entendimiento del precepto reglamentario lleva a considerar que no procederá la concesión de la licencia o procederá la revocación de la autorización previamente concedida cuando se constate que no se cumplen las condiciones exigibles, sea porque se advierten en el titular de la licencia condiciones psíquicas o físicas que no se consideran compatibles con la utilización de armas de fuego, sea por la concurrencia de circunstancias de las que se derive que la posesión y uso de armas comporta un riesgo propio o de terceros.

En este sentido, resulta obligado volver a reiterar el carácter restrictivo de la concesión de permisos o licencias para la tenencia de armas de fuego. En la sentencia de 8 de abril de 2008 (RC 1564/2004), ya reseñada, con cita de sentencias anteriores, se ha destacado el carácter restrictivo que rige esta materia debido al cambio normativo operado por la promulgación del nuevo Reglamento de Armas, aprobado por el Real Decreto 137/1993, de 29 de enero, en comparación con el antiguo Reglamento, aprobado por Real Decreto 2179/1981. En la mencionada sentencia, el Tribunal Supremo dijo: « [...] una cosa es que el procedimiento no haya cambiado y otra cosa es que haya identidad en los preceptos citados. No la hay. Porque claramente se advierte la introducción de un punto de rigor en la nueva reglamentación que no se limita a hablar de discrecionalidades sino que se añade ... que la expedición de la licencia tendrá carácter restrictivo limitándose a supuestos de existencia de riesgo especial o de necesidad". Añadiéndose que "es claro, pues, que bajo la normativa anterior la libertad estimativa que contiene toda potestad discrecional ha sido reducida, pues el otorgamiento queda sujeto a un mandato imperativo muy preciso: la citada potestad de otorgamiento ha de ejercerse de manera restrictiva.».

$\mathrm{Y}$ se ha de recordar que, conforme a una reiterada jurisprudencia de este Tribunal, no existe un derecho subjetivo a la tenencia de armas de fuego, dado que nos hallamos ante una materia sobre la que las autoridades administrativas poseen una amplia facultad discrecional para valorar las circunstancias concurrentes en cada caso concreto. Como es lógico, esta discrecionalidad no supone exclusión de la posibilidad de revisar en vía jurisdiccional los actos administrativos dictados al amparo de aquella potestad, pero ello no implica en ningún caso una restricción del margen de apreciación que corresponde a dichas autoridades, habida cuenta del peligro que representa este tipo de armas, con la consiguiente necesidad 
de un adecuado control administrativo de las mismas. Ciertamente, son numerosas las sentencias en las que el Tribunal Supremo se ha referido al carácter restrictivo de la concesión de permisos o licencias para la tenencia de armas de fuego; así, pueden verse, entre otras, las sentencias de 21 de mayo de 2009 (casación 500/05), 27 de noviembre de 2009 (casación 6374/2005) y 22 de enero de 2010 (casación 459/2006)." Siendo de trascendental importancia no olvidar la singularidad del supuesto que se enjuicia en cada litis, ya que, como ha tenido ocasión de expresar el Tribunal Supremo en múltiples sentencias," el examen de cada caso requiere que sean tomadas en consideración y valoradas las específicas circunstancias que en él concurran".

La valoración de la aptitud para el uso de las armas, a que se refiere el artículo 98.1 del Reglamento citado, según nuestra jurisprudencia, debe basarse en una apreciación global de todos los datos disponibles de la conducta del solicitante, que no resultan ajenos a la concurrencia, o no, de antecedentes penales, o a la cancelación, o no, de los mismos. En este sentido se ha declarado que « La mera carencia de antecedentes penales, o la cancelación de los existentes, no constituyen por sí solas razones suficientes para la concesión o el mantenimiento de la licencia de armas (en este sentido, y respecto de la cancelación de antecedentes penales, STS de 14 de noviembre de 2000, RG 7494/1996), ni puede decirse que solo por no tener antecedentes penales, o por tener cancelados los existentes, se tenga ya derecho a la concesión o al mantenimiento de dicha licencia. Al contrario, por encima de ese dato formal, es preciso apreciar de forma singularizada unas cualidades personales en el interesado que permitan concluir que de la concesión y mantenimiento de la licencia no se seguirá riesgo alguno ni para el propio interesado ni para terceros» ( STS de 21 de enero de 2010 dictada en el recurso de casación $\left.n^{\circ} 7652 / 2005\right)$. Por ello, es esencial a la hora de enjuiciar la decisión judicial impugnada, ponderar si fueron tomadas en consideración y valoradas las específicas circunstancias que en él inciden.

Quedaría incompleta la anterior reseña si no añadiéramos que no nos encontramos en presencia de un procedimiento sancionador, sino ante un particular régimen de autorizaciones administrativas para la tenencia y uso de armas, en razón del peligro de éstas, cuya concesión dependerá de la conducta del peticionario y de las particulares circunstancias que en él concurren, puestas en relación con el interés público que trata de prevenirse. Pero en todo caso debemos tener en cuenta que el ya citado Reglamento de Armas aprobado por Real Decreto 137/93, de 29 de enero , en ningún momento condiciona la obtención de los permisos de armas, al requisito de 
carecer de antecedentes penales en vigor, sino que alude a un concepto más amplio, consistente en la ausencia de peligro en el sujeto, ya que frente a otros sistemas jurídicos que consideran la posesión de armamento como un derecho, nuestro ordenamiento estima que la posesión de armas constituye un peligro para el propio titular y para los demás; de ahí que someta dicha posesión a una serie de requisitos especiales que deben concurrir y cuya inexistencia determina la denegación, la revocación o la falta de renovación de la correspondiente licencia, dado que la ausencia de estos requisitos supone una situación de peligro inadmisible para el resto de la comunidad.

Con todas estas consideraciones jurídicas y jurisprudenciales sobre la materia que nos ocupa, la Sala aprecia que el parecer de la Administración, plasmado en la resolución impugnada, no se acomoda a las prescripciones del artículo 98.1 del Real Decreto 137/1993, de 29 de enero por el que se aprueba el Reglamento de Armas, pues la conducta descrita del ahora recurrente según se declaró en el auto de sobreseimiento, en base a la declaración de una testigo, no integraban los hechos que se le imputaban y tampoco se erigían en el momento de la resolución judicial en riesgo o peligro potencial que pudiera aconsejar y acordar esa revocación, recuérdese que el Ministerio Fiscal no se opuso a la devolución de las armas incautadas y que el Juzgado accedió a su entrega. Todo lo expuesto y razonado es lo que nos determina a estimar el recurso, y anular, dejando sin efecto el acto impugnado y sin que de conformidad con el artículo139 de la LJCA haya lugar a hacer pronunciamiento sobre la condena en las costas causadas en esta instancia.

Vistos los artículos citados y los demás de general y pertinente aplicación, la Sala dicta el siguiente

\section{FALLO}

1.- Estima el recurso contencioso administrativo interpuesto por la representación procesal de don Saturnino contra la resolución de 14 de marzo de 2014 dictada por la Subdelegacion del Gobierno en Granada que desestimó el recurso de reposición deducido el 16 de enero de 2014 contra la resolución de 26 de diciembre de 2013 del Subdelegado del Gobierno en Granada dictada en el expediente NUM000, que revocó la licencia de armas tipo E., acto que anulamos por no ser conforme a Derecho.

2.- Sin expresa condena en las costas.

(St. 17 de octubre de 2017. Sala de Granada. Ponente J.A. Santandreu Moreno) 


\section{BIENES PÚBLICOS.}

Aguas. Pozos en medio privado. Comunicación para su uso no concesión. Procedimiento y límites. Procedencia del uso.

Constituye el objeto de la presente apelación la sentencia que estima parcialmente el recurso interpuesto contra la resolución desestimatoria del recurso de alzada deducido frente a la resolución de 15 de agosto de 2011 del Director General de Planificación y Gestión del Dominio Público Hidráulico que acordaba la disconformidad a la comunicación de uso privativo de aguas públicas por disposición legal a efectos de su inscripción en la Sección B del Registro de Aguas, de un pozo sito en la FINCA000 del término municipal de El Puerto de Santa María, efectuada el 11 de febrero de 1999 a la Confederación Hidrográfica del Guadalquivir.

La sentencia considera que se ha prescindido del procedimiento legal establecido en el art. 88 de la Ley de Aguas (en realidad es del Reglamento del Dominio Público Hidráulico), por falta de audiencia al interesado, pero estima el recurso sólo parcialmente considerando que el órgano judicial no puede resolver la inscripción del aprovechamiento "al no ser objeto del acto administrativo ni estar dotado de la capacidad decisoria sobre su procedencia”.

Contra dicha sentencia se alza la Administración alegando que la norma no contempla trámite de audiencia previo a la decisión de conformidad o disconformidad con la comunicación del aprovechamiento, y no concurre, por tanto, causa alguna de nulidad o anulabilidad de los arts. 62.1 .e ) y 63 de la Ley 30/1992. Por su parte, el interesado se opone a la apelación interesando la confirmación de la sentencia por sus propios razonamientos. De aquí se deriva que el objeto de esta alzada es exclusivamente examinar si se ha prescindido o no del procedimiento legal establecido en el art. 88 del Reglamento del Dominio Público Hidráulico, por falta de audiencia al interesado, como así aprecia la sentencia impugnada que ha sucedido, quedando pues fuera del debate en esta alzada el pronunciamiento judicial contenido en la sentencia relativo a la imposibilidad de resolver la inscripción del aprovechamiento "al no ser objeto del acto administrativo ni estar dotado de la capacidad decisoria sobre su procedencia".

El artículo 52 de la Ley de Aguas 29/1985, de 2 de agosto -actual artículo 54 del Texto Refundido de la Ley de Aguas -, estableció un régimen especial en su apartado 2 al prever que "en las condiciones que reglamentariamente se establezcan, se podrán utilizar en un predio, aguas procedentes de manantiales situados en su interior y aprovechar en él aguas subterráneas, 
cuando el volumen total anual no sobrepase los 7.000 metros cúbicos. En los acuíferos que hayan sido declarados como sobreexplotados, o en riesgo de estarlo, no podrán realizarse nuevas obras de las amparadas por este apartado sin la correspondiente autorización". Ese derecho al uso privativo de las aguas de un predio por disposición legal, se desarrolla en los artículos 84 y siguientes del Reglamento del Dominio Público Hidráulico, aprobado por Real Decreto 849/1986, de 11 de abril. Como declaró la sentencia del Tribunal Constitucional 17/1990, de 7 de febrero, siguiendo la doctrina ya sentada en la anterior 277/1988, de 29 de febrero, lo que dicho precepto establece es "una excepción a la regla general establecida en el artículo 57 -todo uso privativo de las aguas no incluido en el artículo 52 requiere concesión administrativa-, es decir, ese derecho no queda sometido a concesión, sino a la comunicación del titular al Organismo de Cuenca a los efectos procedentes, acreditando la propiedad y adjuntando plano parcelario y otros datos técnicos sobre el aprovechamiento pretendido (artículos 85 y siguientes). En todo caso, como decimos, el volumen total anual no puede sobrepasar los 7.000 metros cúbicos.

Pues bien, constan las siguientes actuaciones por parte del interesado y de la Administración:

En aquella comunicación de 11 de febrero de 1999 se expresaba que el pozo tenía una profundidad de captación de quince metros, y de agua de cinco metros, un diámetro de 240-160 milímetros siendo el tipo de construcción un tubo de PVC de 160 milímetros, que el destino del agua era el uso doméstico y riego por aspersores de 220 metros cuadrados; se expresaba también que se trataba de un chalet, se indicaba que los caudales máximos instantáneo y equivalente eran de 1, 06 y 0,14 litros por segundo, respectivamente, que la finca no tenía otras captaciones, que el pozo estaba a más de treinta metros del aprovechamiento más próximo, y que el volumen total anual a emplear era de 4.500 metros cúbicos.

Consta en el expediente como primera actuación administrativa un requerimiento de documentación en octubre de 2005 para que se aportara plano parcelario catastral y memoria técnica justificativa de las necesidades hídricas.

Al aportar dicha documentación el recurrente alegaba en esa memoria justificativa que en la solicitud de 1999 se puso por error que el volumen total anual a emplear era de 4.500 metros cúbicos cuando era de 500 metros cúbicos anuales, aproximadamente, por destinarse el pozo al riego del 
jardín, y no existir piscina ni utilizarse el agua de la captación para uso doméstico de la vivienda.

Consta a continuación en el mismo expediente un acta de la diligencia de reconocimiento sobre el terreno de 24 de julio de 2007 que no pudo llevarse a cabo porque, según se hacía constar, "tras citarse al solicitante para el reconocimiento de campo de la captación, éste no se presentó a dicha citación", obrando la efectiva notificación.

Consta después la propuesta de resolución efectuada por la Jefe de Servicio de Gestión del Dominio Público Hidráulico en la que, invocando el art. 173 del Reglamento del Dominio Público Hidráulico, aprobado por Real Decreto 849/1986, de 11 de abril, y dado que que la captación se encuentra dentro de los perímetros de protección del acuífero 05.58: Puerto de Santa María, definidos en la Orden de 13 de agosto de 1999 por la que se aprueban las determinaciones de contenido normativo del Plan Hidrológico de la cuenca del Guadalquivir, se concluye que el aprovechamiento no es compatible con las limitaciones establecidas en la citada Orden. La resolución de 15 de agosto de 2011 del Director General de Planificación y Gestión del Dominio Público Hidráulico acoge esta propuesta y acuerda la disconformidad a la comunicación.

Así las cosas el recurso ha de prosperar. Lo que establece el art. 88 ya citado es lo siguiente: "1. El Organismo de cuenca, con reconocimiento sobre el terreno si lo considera preciso, comprobará la suficiencia de la documentación aportada y la adecuación técnica de las obras y caudales que se pretendan derivar para la finalidad perseguida.

2. En caso de conformidad, lo comunicará al dueño de la finca, procediendo a inscribir la derivación a su favor, con indicación de sus características.

3. En caso de disconformidad lo comunicará, asimismo, al dueño del predio, señalándose las omisiones de la documentación, la causa de inadecuación técnica de las obras o caudales, las modificaciones que en su caso sea preciso introducir o la causa de ilegalidad de la derivación, prohibiendo al mismo tiempo la misma, sin perjuicio de que el usuario pueda reiterar su petición una vez corregidas aquéllas".

El acuerdo de disconformidad no se hizo prescindiendo del procedimiento legalmente establecido, sino conforme a él. Hubo un requerimiento por la Administración para se aportara la documentación que faltaba, plano parcelario catastral y memoria técnica justificativa del volumen de agua a emplear; hubo una desatención por el interesado a la convocatoria que se efectuó para la práctica de la diligencia de reconocimiento sobre el terreno; 
sin que el precepto citado exija nueva audiencia antes del pronunciamiento sobre la disconformidad por diversos defectos o insuficiencias en la documentación presentada "sin perjuicio de que el usuario pueda reiterar su petición una vez corregidas aquéllas".

Además, resultó que la disconformidad se basaba en hallarse la captación dentro de los perímetros de protección del acuífero 05.58: Puerto de Santa María, lo que para la Administración era un motivo impeditivo para prestar la conformidad a la comunicación, invocando para ello el art. 173 del Reglamento del Dominio Público Hidráulico , que en su apartado 1 señala que "el Organismo de cuenca podrá determinar perímetros de protección del acuífero en los que será necesaria su autorización para la realización de obras de infraestructura, extracción de áridos u otras actividades e instalaciones que puedan afectarlo (art. 54.3 de la LA)", y en el apartado 4 dispone que "dentro del perímetro establecido, el Organismo de cuenca podrá imponer limitaciones al otorgamiento de nuevas concesiones de aguas y autorizaciones de vertido, con objeto de reforzar la protección del acuífero. Dichas limitaciones se expresarán en el documento de delimitación del perímetro y se incluirán en el Plan Hidrológico de la cuenca”. Este motivo fue combatido en el recurso de alzada por el interesado, y en la misma instancia, como lo ha podido hacer en esta apelación de impugnarse el pronunciamiento de la sentencia estimando sólo parcialmente el recurso.

De conformidad con lo dispuesto en el artículo 139.2 de la Ley de la Jurisdicción, no procede pronunciamiento de condena al pago de las costas causadas en esta instancia.

(St. de 19 de octubre de 2017. Sala de Sevilla. Ponente V Valpuesta Fernández)

\section{EXPROPIAGIÓN FORZOSA.}

Valoración de fincas rústicas; método aplicable. Motivación de los acuerdo del jurado de Expropiación.

El objeto del presente recurso contencioso administrativo es la resolución de fecha de 17-6-11 dictada por el Jurado Provincial de Expropiación Forzosa en Almería fijando el justiprecio de la finca CUE 137 afectada por la obra de la autopista AP-7, que valora el suelo expropiado como de labor regadío a 3, 60 euros/ m2 (valorando por este importe una superficie de $1.780 \mathrm{~m} 2$ ) y concediendo indemnización por Ocupación temporal de $2.348 \mathrm{~m} 2$ y por servidumbre de paso sobre $73 \mathrm{~m} 2$; fijando un total de 6.691, 61 euros como justiprecio más $5 \%$ del premio de afección. 
La parte recurrente, en su escrito de demanda, solicita la estimación del recurso, con nulidad del acto administrativo recurrido, justificándolo en las siguientes argumentaciones:

1.- Por la DT 3a de la Ley del Suelo 8/07 es de aplicación al presente expediente lo establecido en el art. 23 de la Ley 6/98 según el cual las valoraciones de suelo se efectuarán con arreglo a los criterios establecidos en la citada ley.

2.- El acuerdo del Jurado es nulo de pleno derecho por infracción de los arts. 9.3 y 24 CE , 35 LEF y 54 y 89 Ley 30/92. El acuerdo carece de la motivación exigida legalmente en relación a la procedencia e idoneidad de los datos y parámetros utilizados.

3.- El acuerdo del Jurado es nulo de pleno derecho por infracción del art. 26 TRLS, que establece que inicialmente el valor del suelo no urbano se determinará por el método de comparación a partir de fincas análogas, y sólo cuando no sea posible aplicarlo procederá el método de capitalización de rentas. En el presente expediente deben ser considerados como valores comparables los preciso publicados por el Ministerio de Agricultura, Pesca y Alimentación a partir de las encuestas sobre el precio de la tierra, que han sido determinados en función de datos estadísticos procedentes de los boletines oficiales de estadística agraria.

El precio determinado por el Jurado es muy superior a los precios reales establecido para fincas agrícolas análogas a la de este expediente, atendidos los precios de venta de fincas análogas de suelo labor regadío, que se valoran a 2, 55 euros/m2 según tablas de precios fijadas por la Consejería de Agricultura o de 1, 35 euros/ m2 fijados en contratos de compraventa de fincas análogas o de 1,44 euros/m2 para fincas expropiadas para la misma obra y adquiridas de forma amistosa.

Consecuentemente, la parte recurrente insta la estimación del presente recurso con anulación del acuerdo del Jurado y retroacción de las actuaciones a la sesión del Jurado para fijación del justiprecio, y subsidiariamente, la anulación del acuerdo impugnado y la fijación del justiprecio en la cantidad de 2.953, 23- euros.

Frente a ello, la Administración demandada interesa la desestimación del recurso contencioso administrativo y la confirmación de la resolución dictada por el Jurado de Expropiación Forzosa.

Respecto a la motivación de las resoluciones administrativas, cuestión que constituye una constante de nuestro ordenamiento jurídico, se proclama en el artículo 54 de la Ley 30/1992, de 26 de noviembre, de Régimen Jurídico de 
las Administraciones Públicas y del Procedimiento Administrativo Común y tiene por finalidad que el interesado conozca los motivos que conducen a la resolución de la Administración, con el fin, en su caso, de poder rebatirlos en la forma procedimental regulada al efecto. Motivación que, a su vez, es consecuencia de los principios de seguridad jurídica y de interdicción de la arbitrariedad enunciados por el apartado 3 del artículo 9 de la Constitución y que también, desde otra perspectiva, puede considerarse como una exigencia constitucional impuesta no sólo por el artículo 24.2 CE, sino también por el artículo 103 (principio de legalidad en la actuación administrativa).

El Tribunal Constitucional en su sentencia 116/1998 siguiendo una marcada y sostenida doctrina (Sentencias 58/1993 , 28/1994, 153/1997 y 446/1996) señala que el deber de las motivaciones no autoriza a exigir un razonamiento exhaustivo y pormenorizado de todos los aspectos y perspectivas que las partes puedan tener de las cuestiones a decidir, sino que deben considerarse suficientemente motivadas aquellas resoluciones que permiten conocer cuáles han sido los criterios jurídicos esenciales que fundamentaron la decisión, es decir la "ratio decidendi" que ha determinado aquella (Sentencia del Tribunal Supremo 115/96 ).EI Tribunal Supremo, en sentencia de 15 de octubre de 1981 ya afirmaba que "la motivación de los actos administrativos es la exteriorización de las razones que sirvieron de justificación, de fundamento a la decisión jurídica contenida en el acto, como necesaria para conocer la voluntad de la Administración, tanto en cuanto a la defensa del particular que por omitirse las razones se verá privado, o al menos, restringido, en sus medios y argumentos defensivos, como al posible control jurisdiccional si se recurriera contra el acto. En fin, la suficiencia de la motivación no puede ser apreciada apriorísticamente con criterios generales, requiriendo por el contrario examinar el caso concreto para comprobar si, a la vista de las circunstancias concurrentes, la resolución impugnada ha cumplido o no este requisito. Por lo demás la doctrina jurisprudencial ( Sentencia de 21 de enero del 2003 de la Sala Tercera del Tribunal Supremo) tiene declarado, de una parte, que la motivación de un acto o resolución administrativa, conforme, entre otros, a lo dispuesto en los artículos 53 y 54 de la Ley 30/1992, exige que en los mismos se concrete la actuación o abono que se pide o exige del particular y la razón o causa por la que se pide o exige, a fin de que el afectado pueda conocer con claridad y precisión lo que se pide, la causa, razón o motivo que lo origina y articular en base a ello adecuadamente su defensa; y de otra parte, conforme a reiterada doctrina del Tribunal Constitucional (Sentencias de 25.4.94 y 25.3.96) y de la propia Sala Tercera del Tribunal Supremo (Sentencias de 25.1.00 y 4.11.02) la motivación de una 
resolución puede hacerse bien directamente, bien por referencias a informes o dictámenes obrantes en las actuaciones.

En consecuencia, no cabe confundir la brevedad y concisión de términos de los actos administrativos resolutorios con la falta de motivación, ni es necesario exponer los motivos de la decisión cuando están presupuestos en la misma, bastando para estimar cumplido ese requisito con que, aún sumariamente, se indique de forma inequívoca el fundamento de la resolución. En verdad, la motivación del acto administrativo no depende del grado de suficiencia considerado necesario por los particulares interesados, sino que basta con que se pueda conocer con la mayor certeza posible la verdadera voluntad del órgano actuante para que se entienda suficientemente motivado. En suma, la motivación escueta o sucinta de todo acto administrativo, si es suficientemente indicativa, no equivale a ausencia de motivación ni acarrea su nulidad, pues la sucinta referencia motivadora no requiere una exhaustiva y completa referencia táctica y jurídica del proceso conformador de la voluntad administrativa.

Del acuerdo del Jurado se destaca que, aunque somera en determinados puntos, la motivación ha de entenderse suficiente para cumplimentar las exigencias determinadas en el art. 54 Ley 30/92.

En primer lugar se cuestiona el método de valoración utilizado por el Jurado de Valoración.

Para resolver esta cuestión ha de determinarse cuál es la normativa aplicable. Señala el artículo 36.1 de la L.E.F que “ Las tasaciones se efectuarán con arreglo al valor que tengan los bienes o derechos expropiables al tiempo de iniciarse el expediente de justiprecio, sin tenerse en cuenta las plusvalías que sean consecuencia directa del plano o proyecto de obras que dan lugar a la expropiación y las previsibles para el futuro ".

La Sentencia del Tribunal Supremo de 20 de enero de 2003, que ha tenido su continuación en las de 23 de febrero y 9 de junio de 2005 y 79 diciembre 2006, lo deja bien claro:'... la fecha que determina la legislación a aplicar es la de la aprobación de la necesidad de ocupación y de la relación de los bienes expropiados que, indudablemente, es anterior a la fecha de requerimiento para el levantamiento del acta previa a la ocupación [...] aun cuando la valoración del bien haya de efectuarse con referencia al momento en que el recurrente es citado y requerido para la presentación de la hoja de aprecio conforme dispone elartículo 36.1 de la Ley de Expropiación Forzosa “".

En resumen, a la expropiación en general se aplica la norma que se hallare en vigor en el momento en que se inicia el expediente expropiatorio, esto es, 
cuando se adopta el acuerdo de necesidad de la ocupación; y la valoración de los terrenos se fija en atención a la fecha en que comienza el expediente o pieza separada de justiprecio, que es el momento en que se requiere al propietario expropiado a fin de que presente la hoja de aprecio.

Y con estas consideraciones, el requerimiento de hoja de aprecio particular al propietario es la fecha determinante para entender iniciado el expediente de justiprecio, y por lo tanto, la fecha a la que debe referirse la calificación de los bienes a expropiar a efectos de su valoración.

Con ello ha de estarse a la legislación vigente al tiempo de iniciarse el expediente de justiprecio, que debe ser la Ley del Suelo 6/98.

En relación al suelo rústico, el art. 26 de la Ley 6/1998, de 13 de abril del Régimen del Suelo y Valoraciones estatuía que " 1 . El valor de este suelo se determinará por el método de comparación a partir de valores de fincas análogas. A estos efectos, la identidad de razón que justifique la analogía deberá tener en cuenta el régimen urbanístico, la situación, tamaño y naturaleza de las citadas fincas en relación con la que se valora, así como, en su caso, los usos y aprovechamientos de que sean susceptibles. 2. Cuando por la inexistencia de valores comparables no sea posible la aplicación del método indicado en el punto anterior, el valor del suelo no urbanizable se determinará mediante la capitalización de las rentas reales o potenciales del suelo, y conforme a su estado en el momento de la valoración” .

El criterio preferente para la valoración de fincas rústica es el de comparación con otras análogas (apartado 1), reservando al de capitalización de rentas (apartado 2) un papel subsidiario para el caso de que no pueda aplicarse el primero por falta de elementos de contraste; ambos métodos no son alternativos [ sentencias de 22 de junio de 2005 (casación 3162/02, FJ $2^{\circ}$ ) y 16 de mayo de 2007 (casación 10101/03, FJ 2o).

Siendo aplicable la ley de 98 el primer método de valoración de la finca es la de comparación con fincas análogas, para lo cual la orden Ministerial ECO/805/2003, de 27 de marzo, exige disponer de información suficiente sobre al menos seis transacciones u ofertas de comparación que reflejen adecuadamente la situación actual del mercado. Ni estas seis referencias se ha aportado por la parte recurrente para aplicar el método comparativo, ni se puede aplicar, como pretende la parte recurrente, el estudio estadístico realizado por el Ministerio de Agricultura sobre precios de suelo rústico en la provincia de Almería, pues tiene gran indeterminación respecto de la finca en concreto a valorar. Así, la normativa aplicable determina que debe aplicarse el método de capitalización de rentas, y al no tenerse datos 
concretos y específicos de la producción de la finca, debe estarse a una valoración potencial de los rendimientos dada la condición de la finca.

Por ello, procede aplicar el método de capitalización de rentas, que no se contrapone de una forma adecuada por la parte recurrente que viene a reproducir las valoraciones establecidas en su hoja de aprecio, atendiendo a las justificaciones establecidas por el Jurado respecto de las condiciones propias de la finca a expropiar.

Lo anteriormente expuesto determina la aplicación del criterio expuesto por elJurado Provincial de Expropiaciones forzosas, el que no ha sido desvirtuado por la parte recurrente, debiendo recordar que, en materia expropiatoria, según consolidada doctrina jurisprudencial, es relevante el principio del favor acti, en cuya virtud se concede a los Acuerdos del Jurado de Expropiación Forzosa (doctrina trasladable a las Comisiones Territoriales de Valoración de las Comunidades Autónomas) una presunción de legalidad y acierto que los hacen merecedores de ser acogidos con el crédito y autoridad que se desprende de su doble composición técnica y jurídica y de su especialización, si bien tal presunción, como iuris tantum que es, puede, y debe, ser revisada en esta vía jurisdiccional, tanto en los supuestos de notorio error de hecho o de infracción de preceptos legales, como en aquellos otros en que se acredite una desajustada apreciación de los datos materiales o la valoración no esté en consonancia con la resultancia fáctica del expediente, representativos de un desajustado justiprecio acreditativo de la falta de compensación material para el expropiado que el instituto de la expropiación comporta, aunque, a la luz de tales principios -los de sustitución patrimonial íntegra y equivalencia consustantiva-, lo que no cabe es sustituir pura y simplemente el criterio del Jurado por el del expropiado, ni siquiera por el del Tribunal, ni aun por el dictamen pericial practicado en autos, a menos que este dictamen tenga la adecuada fuerza de convicción por apoyarse en presupuestos fácticos y legales que avalen sus conclusiones. También se ha dicho por esta Sala que la valoración del Jurado está amparada por la presunción de acierto de las resoluciones de esta clase de órganos, no siendo dable aceptar que la prueba que se aporte en contra de la corrección del acuerdo del JEF sea el informe que se adjunte por el recurrente junto con su hoja de aprecio, ya que se incorpora al expediente administrativo a su instancia y, por tanto, no reúne los requisitos necesarios para desvirtuar la presunción de legalidad y acierto de las resoluciones del Jurado Provincial de Expropiación (sentencias del Tribunal Supremo de 30 de junio de 1989,18 de mayo de 1992, 30 de marzo de 1993,12 de abril de 1995, pues el informe aportado por el interesado con su hoja de aprecio tiene carácter necesariamente parcial (sentencias de 30 de 
junio de 1992, de 26 de enero y 30 de marzo de 1993), por lo que no puede prevalecer por sí solo sobre los acuerdos del Jurado.

A este respecto, insistiendo en la misma idea, establece la sentencia del Tribunal Supremo, de fecha 26 de noviembre de 1998 (ponente, Excmo. Sr. D. Francisco González Navarro), que: "En sentencia de 3 de mayo de 1993 (R. 3697) la Sala 3a, Sección 6a, del Tribunal Supremo manifiesta que es jurisprudencia consolidada de esta Sala del Tribunal Supremo que las resoluciones de los Jurados gozan de la presunción "iuris tantum" de veracidad y acierto en sus valoraciones, que puede quedar desvirtuada en vía jurisdiccional cuando se acredite un notorio error material o una desajustada apreciación de los datos fácticos probatorios o infracción de los preceptos legales, reveladores de que el justiprecio señalado no corresponde al valor del bien o derecho expropiado (Sentencias de esta Sección Sexta de 12-3-1991,46-1991, 14-10-1991 y 27-2-1991), de manera que no es legítimo sustituir, sin pruebas que lo justifique, el criterio valorativo del Jurado por el del Tribunal".

En los mismos términos se expresa la sentencia del Tribunal Supremo, de fecha 20 de noviembre de 1997 (ponente, Excmo. D. Juan José González Rivas), cuando señala que: "A mayor abundamiento, es de tener en cuenta que esta Sala, en reiterada jurisprudencia (sentencias de 28 de noviembre de 1986, 30 de junio y 20 de octubre de 1986,17 de mayo de 1989, 8 de marzo de 1990 y otras muchas posteriores) ha afirmado la presunción de veracidad y acierto de las decisiones en materia de justiprecio que adoptan los Jurados de Expropiación Forzosa, reconociendo la capacidad técnica y jurídica de sus componentes y la independencia que reviste sus juicios al no encontrarse vinculados a los intereses en juego, mientras no se demuestre haber sufrido un error o desviación de los que resulte manifiestamente injusta la indemnización fijada, criterio este último reiterado por el Abogado del Estado. En consecuencia, para desvirtuar dicha presunción no hubiesen sido suficientes los dictámenes e informes aportados por las partes, sin las garantías y formalidades propias de la prueba practicada en el proceso, que además no se ha practicado por la Sala de instancia, si bien la jurisprudencia mitiga los excesos de la expresada presunción, poniendo de manifiesto que un acuerdo sin fundamentar o concretar suficientemente por parte del Jurado, no puede prevalecer, a salvo la existencia de otros elementos probatorios frente a una prueba pericial practicada regularmente en el proceso si ésta tiene carácter circunstancial y razonado y su fundamentación resulta convincente y comporta, en definitiva, la necesidad de ponderar la valoración del Jurado, teniendo en cuenta los elementos de tipo argumental en que se apoya, lo que no ha sucedido en la cuestión planteada". 
El Jurado estableció como motivación para valorar la finca en cuestión a razón de 3, 60 euros/m2 por su consideración de suelo de labor de regadío, destacando la información del vocal técnico ingeniero agrónomo, tras su visita a la finca de referencia, sobre la potencialidad intrínseca y extrínseca agronómica de la finca (factores climatológicos, edafológicos, orográficos, etc), aspectos referidos por la Administración demandada en la resolución impugnada.

Se han utilizado unas valoraciones que se establecen de forma constante en otros expedientes de justiprecio de expropiaciones efectuada para la realización de la misma obra pública.

Y esta motivación ha de estimarse suficiente a los efectos de determinar el valor del suelo expropiado, sin que pueda prevalecer el importe inferior defendido por la beneficiaría recurrente, y sin que proceda, como pretende la parte recurrente, fijar un precio como si de suelo de matorral se tratase, no habiendo desplegado prueba alguna tendente a determinar que fuera ésta la categoría del suelo en vez de la determinada por el Jurado.

No procede la condena en costas, de conformidad con el art. 139.1 ley de jurisdicción contenciosa administrativa de 13 de julio de 1998, al no mediar mala fe o temeridad en la parte recurrente, en su redacción anterior a la Ley $37 / 11$.

\section{FALLAMOS}

Que debemos desestimar y desestimamos el recurso contencioso administrativo formulado por la representación procesal de la entidad mercantil Autopista de la Costa Cálida contra la resolución de fecha de 176-11 dictada por el Jurado Provincial de Expropiación Forzosa en Almería fijando el justiprecio de la finca CUE 137 afectada por la obra de la autopista AP-7; y consecuentemente, se confirma el acto administrativo impugnado por ser ajustado a derecho.

Sin especial pronunciamiento sobre condena en costas.

(St. de 16 de octubre de 2017. Sala de Granada. Ponente M ${ }^{a}$ Luisa Martín Morales).

\section{XV.JURISDICGIÓN GONTENCIOSO ADMINISTRATIVA.}

Competencia de la Jurisprudencia Contesioso-Administrativo para la declaración de validez de la relación funcionarial de interinos. 
Mediante el auto apelado el Juzgado de lo Contencioso-Administrativo número Uno de Jerez de la Frontera, declaró la inadmisión del recurso interpuesto contra la desestimación presunta del requerimiento dirigido a la Consejería de Igualdad y Políticas Sociales de la Junta de Andalucía para que se declarase que su relación con la Administración es laboral indefinida a tiempo completo desde el 18 mayo 2007 por considerar que la competencia es de ia jurisdicción social.

Asunto semejante al que nos ocupa ha sido ya resuelto por esta Sala en sentencias, de 27 de septiembre de 2017, Rec. de apelación 493/2017, con criterio que, por tanto, hemos de reiterar. Así:” Debemos partir de la premisa de que la actora presta servicios como funcionaría interina y por tanto conforme al artículo 8.2.b del Real Decreto Legislativo 5/2015, de 30 de octubre, por el que se aprueba el texto refundido de la Ley del Estatuto Básico del Empleado Público, se integra en el concepto de empleado público.

Por tanto, si bien la pretensión ejercitada consiste en una declaración de que su relación con la Administración es laboral indefinida a tiempo completo, al tratarse de una funcionaría interina y no personal laboral, no resulta aplicable el artículo 2.a de la Ley 36/2011 de 10 de octubre, reguladora de la Jurisdicción Social, pues no existe contrato de trabajo ni relación laboral, sino su sometimiento a la normativa administrativa, régimen jurídico perfectamente diferenciado del régimen del personal laboral.

En este sentido la sentencia del Tribunal Supremo de 12 julio 2002 (RJ 2002\9332), declaró que "el orden social de la jurisdicción carece de competencia para conocer pretensiones como la que aquí se deduce porque en realidad se trata de decidir sobre la validez de la relación funcionarial..., lo que corresponde al orden contencioso-administrativo, como se desprende de lo prevenido por el artículo 9.4 de la Ley Orgánica del Poder Judicial y por el artículo 1 de la Ley de la Jurisdicción Contencioso-Administrativa “".

En consecuencia, procede la revocación del auto impugnado y la declaración de que corresponde a esta jurisdicción contencioso-administrativa el conocimiento del presente asunto ".

En esta misma dirección se expresó también la sentencia del TSJ del País Vasco de 21-6-11 (rec. 941/09 ): “...por lo que no cabe sino concluir que competente es el Orden Jurisdiccional Contencioso-Administrativo, porque lo que está en cuestión es la validez jurídica de la relación funcionarial interina, que es la que se encontraba vigente y de la que debemos partir, por estar en un supuesto en el que, en contra de algunos de los analizados por la jurisprudencia del Tribunal Supremo al resolver conflictos de competencia, 
el demandante sí llegó a tomar posesión como funcionario interino, por lo que estamos ante un supuesto en el que la relación de trabajo de régimen laboral se transformó en relación funcionarial como interino".

Por las mismas razones, y por congruencia con lo ya resuelto por esta misma Sala y Sección, procede la estimación del recurso.

Al no haber, a nuestro juicio, circunstancias que justifiquen otro distinto pronunciamiento, de acuerdo con el art. 139.2 L.J.C.A . y dado el sentido de esta resolución, no procede hacer expresa imposición de las costas de esta segunda instancia.

Vistos los artículos citados y demás de general y pertinente aplicación.

\section{FALLAMOS}

PRIMERO.- Estimar el recurso de apelación interpuesto por la Consejería de Igualdad y Políticas Sociales de la Junta de Andalucía, contra el Auto de fecha 4 de abril de 2017 dictado por el Juzgado de lo ContenciosoAdministrativo número Uno de Jerez de la Frontera en el procedimiento abreviado número 106/2017 que debemos revocarlo, y lo revocamos, declarando que la jurisdicción competente para el conocimiento del presente asunto es la jurisdicción contencioso-administrativa, debiendo devolverse el procedimiento al Juzgado de procedencia para que continúe con su tramitación.

SEGUNDO.-No hacer expresa declaración sobre pago de costas procesales causadas en esta instancia.

(St. de 10 de octubre de 2017. Sla de Sevilla. Ponente P. Vargas Cabrera)

\section{XX.RESPONSABILIDAD.}

No se aprecia responsabilidad de la Administración que deja cemento en la calzada con la que choca un peatón pues el peatón "debía haber prestado mayor atención al estado de la calle. Nexo de causalidad.

La sentencia de instancia desestima el recurso contencioso, señalando que si bien existe conformidad en cuanto a los hechos, esto es, sobre la forma de producirse el accidente, no hay situación de riesgo de la que derivar el nexo casual entre el servicio público y los daños.

Considera que la necesaria relación de causalidad no se produce entre el funcionamiento del servicio público y los daños, dado que el hecho que 
provoca la caída, existencia de restos de hormigón en la calzada, no tiene entidad suficiente para provocar el accidente. Se dice así que la recurrente podría deambular por el acerado, así como que debió advertir y percatarse de los restos de hormigón evitando así la caída.

El recurso de apelación combate los dos pronunciamientos que emplea la sentencia para desestimar el recurso.

En primer lugar señala que la caída se produce el día de mercadillo, con lo que la recurrente al deambular por la calzada, lo hace en un momento en que no hay tráfico rodado, y por tanto la calle sí está habilitada para el paso de peatones.

En segundo lugar se señala que la caída tiene como causa directa restos de hormigón existentes en la calzad, no perceptible y que tenían la entidad suficiente ara provocar el accidente como así ocurrió.

El Ayuntamiento de Chucena impugna el recurso señalando que la calle por la que deambulaba la recurrente, por más que tuviera el tráfico restringido, no era una calle peatonal. Así como que la caída se debió a la falta de cuidado de la recurrente dado la escasa entidad del desperfecto.

Por la compañía de seguros codemandada se impugna asimismo el recurso de apelación imputando a la negligencia de la recurrente la caída, negando por otra parte la existencia de nexo imputable al Ayuntamiento demandada.

A la hora de examinar la deambulación diligente que le es exigible al peatón, la jurisprudencia del Tribunal Supremo (entre otras sentencia de 17 de mayo de 2001 ) y la práctica emanada de los Tribunales Superiores de Justicia (sentencias del TSJ de Andalucía, Sala de Sevilla de 21 de septiembre de 2005 y 5 de enero de 2006) atienden como factor primordial a la previsibilidad del elemento que colocado en la vía pública obstaculiza el paso del peatón. De manera que cuando el obstáculo es un medio usual de la vía pública, derivado de un funcionamiento correcto del servicio público, $\mathrm{y}$ sin perjuicio de que incluso de este funcionamiento normal también puede derivar responsabilidad, lo norma al es considerar que la relación causal se rompe por la falta de previsión del peatón ante ese obstáculo. Así será el caso cuando se trate de bolas o monolitos para evitar el aparcamiento, farolas o semáforos, o bancos y papeleras todos ellos correctamente situados. En estos casos, la utilización normal de estos elementos en la vía pública, y la previsibilidad de los mismos determina a que cualquier golpe del peatón con ellos, les sea imputable al mismo por cuanto que lo contrario supondría admitir que es posible, lógico y razonable que cuando se camina por la calle, se tropiece de forma habitual con eso mobiliario urbano. 
Ahora bien, cuando el golpe se produce no con este tipo de mobiliario urbano, sino con elementos impropios, o con parte de ese mobiliario urbano incorrectamente colocado, de manera que la existencia del mismo no es previsible ni esperable, cuñas de madera para el acceso de vehículos a garajes en lugar de vados, losetas levantadas, alcantarillas destapadas, mobiliario urbano arrancado y desplazado de su lugar, se genera un riesgo para los viandantes no previsible ni justificado, y con el que por tanto estos no tienen por que contar. De manera que el golpe con estos por parte de un peatón, determina inicialmente la efectiva existencia de relación causal, que solo será modulabe o llegará a desaparecer cuando se pruebe por quien lo alega la concurrencia de culpa o negligencia por parte del viandante.

No discutido en el caso de autos la forma de producirse el accidente, lo que procede resolver es si hay o no responsabilidad administrativa en el hecho causal determinante de los daños.

Y entiende este Tribunal que en el caso de autos, por más que la calle pudiera estar ese día cortada al tráfico, desde el momento que la recurrente decide cruzar la calle por la vía, debe extremar el cuidado por tratarse de una espacio que inicialmente no está destinado al paso de personas y sí al paso de vehículo. De modo que las exigencias de mantenimiento de esa espacio no pueden ser las mismas que se exigen cuando el paso está previsto de forma exclusiva para los peatones.

Al cruzar la calle la recurrente no incurrió en ninguna infracción, pero sí se debe prestar una mayor atención al estado de la calle.

Con lo expuesto debemos concluir que en el caso de autos la imputación de las lesiones no se debe realizar a la administración demandada, y sí a la propia conducta de la recurrente.

En el caso de autos y no obstante la desestimación del recurso contencioso, entendemos que no procede a la visa de los hechos realizar pronunciamiento en materia de costas.

\section{FALLAMOS}

Que debemos desestimar el recurso de apelación formulado por la recurrente contra la resolución que se dice en el antecedente primero de esta sentencia, la cual confirmamos; sin costas.

(St. de 18 de octubre de 2017. Sala de Sevilla. Ponente J.M. Jiménez Jiménez) 


\section{URBANISMO Y VIVIENDA.}

Plan de protección del litoral. Nulidad por aprobarlo el Consejo de Gobierno en funciones.

Constituye el objeto de este recurso la conformidad a derecho del Plan de Protección del Corredor Litoral de Andalucía, aprobado por Decreto 141/2015, de 26 de mayo, de la Consejera de Medio Ambiente y Ordenación del Territorio de la Junta de Andalucía, publicado en el BOJA num. 139 de 20 de julio de 2015.

La recurrente en su demanda alegó la falta de competencia del Consejo de Gobierno para aprobar el plan por hallarse en funciones. Que se incurriría en omisión de informes preceptivos (de evaluación de impacto de género, de la Consejería de Cultura y Deportes, del Consejo de Participación del Espacio Natural de Doñana, de las Juntas Rectoras de los Parques Naturales de Bahía de Cádiz, La Breña y Marisma de Barbate y Tejeda, Almijara y Alhama, de la Comisión de Protección Civil de Andalucía, sobre la repercusión del Plan en los derechos de la infancia y de evaluación de impacto de salud), y concurrían informes desfavorables de la Dirección General de Aviación Civil del Ministerio de Fomento y del Ministerio de Defensa; concurría una insuficiencia de la memoria económica; se incumplía la finalidad de la evaluación ambiental estratégica, y, en todo caso, era insuficiente la memoria ambiental. Se vulnerarían los principios constitucionales de segundad jurídica y de confianza legítima y de retroactividad de las disposiciones retroactivas, vulneración de la autonomía local e inexistencia del presupuesto de urgente necesidad con relación a la utilización abusiva invocada del decreto ley. Se infringían las previsiones del art. $43 \mathrm{f}$ de la LOTA por falta de identificación de las determinaciones de los planes subordinados que deban ser objeto de adaptación y de justificación de las alteraciones propuestas para los mismos. Se incurría en falta de motivación en la adscripción de los sectores y ámbitos a las categorías de protección del Plan con vulneración del principio de interdicción de la arbitrariedad y extralimitación en el ejercicio de la potestad de ordenación territorial.

La demandada se opuso al recurso interesando su desestimación y en lo que se refiere a la primera cuestión formal alegada, la falta de competencia del Consejo de Gobierno por encontrarse en funciones, alegó invocando las previsiones de los artículos 21 de la ley 50/97 y 37 de la ley 6/06, considera que nos encontramos ante un supuesto que se engloba (conforme al apartado 3 del art. 37)en "despacho ordinario de asuntos públicos" establecido en sentencia 2 de diciembre de 2005 TS (161 /2004). El Gobierno en funciones 
no puede adoptar decisiones políticas, lo que incluye la presentación de proyecto de leyes y aprobación de proyecto de la ley de presupuestos, pero el decreto impugnado carece de toda orientación política. La aprobación del Plan y formulación viene impuesta por el legislador. Ley 1/94 de 11 de enero modificada por Decreto ley $5 / 12$, y sujeta a plazo de dos años y seis meses (DA Única del Decreto ley 5/12 modificado por Decreto ley 15/14). La tramitación se inició en enero de 2013 y el plazo se encontraba pronto a vencer a la fecha en que se aprueba el Decreto de 26 de mayo de 2015.

Entrando a examinar en primer lugar, por su carácter formal y prioritario, la posible falta de competencia del Consejo de Gobierno de la Junta de Andalucía para aprobar el Plan, por hallarse en funciones, que de estimarse dispensaría a esta Sala del enjuiciamiento de las demás cuestiones formuladas en la demanda, debemos señalar que esta cuestión ha sido tratada y resuelta en nuestra reciente Sentencia de 7 de septiembre de 2017 dictadas en recurso número 717/2015 (sus razonamientos y decisión han sido reiterados en las de fecha 14 de septiembre de 2017 recaídas en los recursos números 671 /2015,711 /2015 y 721 /2015) en las que que, apreciándose la referida falta de competencia, se acordaba la nulidad de pleno derecho del Decreto 141/2015, de 26 de mayo, objeto de estos autos, de aprobación del Plan de Protección del Corredor Litoral de Andalucía; por lo que en base a los principios de seguridad jurídica, unidad de doctrina e igualdad en la aplicación e interpretación de la Ley nos remitiremos a esas nuestras anteriores decisiones, cuyos argumentos reproducimos seguidamente.

El régimen jurídico del Gobierno en Funciones se contempla en la Constitución, que en su art. 101.1, establece que el Gobierno cesa tras la celebración de elecciones generales, en los casos de pérdida de la confianza parlamentaria previstos en la Constitución, o por dimisión o fallecimiento de su Presidente. En su apartado 2, indica que el Gobierno cesante continuará en funciones hasta la toma de posesión del nuevo Gobierno.

La normativa estatal lo regula en la Ley del Gobierno ( Ley 50/1997, de 27 de noviembre), en cuyo art. 21 expresa lo siguiente:

1. El Gobierno cesa tras la celebración de elecciones generales, en los casos de pérdida de confianza parlamentaria previstos en la Constitución, o por dimisión o fallecimiento de su Presidente.

2. El Gobierno cesante continúa en funciones hasta la toma de posesión del nuevo Gobierno, con las limitaciones establecidas en esta Ley.

3. El Gobierno en funciones facilitará el normal desarrollo del proceso de formación del nuevo Gobierno y el traspaso de poderes al mismo y limitará 
su gestión al despacho ordinario de los asuntos públicos, absteniéndose de adoptar, salvo casos de urgencia debidamente acreditados o por razones de interés general cuya acreditación expresa así lo justifique, cualesquiera otras medidas.

4. El Presidente del Gobierno en funciones no podrá ejercer las siguientes facultades:

a) Proponer al Rey la disolución de alguna de las Cámaras, o de las Cortes Generales.

b) Plantear la cuestión de confianza.

c) Proponer al Rey la convocatoria de un referéndum consultivo.

5. El Gobierno en funciones no podrá ejercer las siguientes facultades:

a) Aprobar el Proyecto de Ley de Presupuestos Generales del Estado.

b) Presentar proyectos de ley al Congreso de los Diputados o, en su caso, al Senado.

6. Las delegaciones legislativas otorgadas por las Cortes Generales quedarán en suspenso durante todo el tiempo que el Gobierno esté en funciones como consecuencia de la celebración de elecciones generales.

La normativa autonómica se contrae al art. 120 del Estatuto de Autonomía de Andalucía, aprobado por la Ley Orgánica 2/2007, de 19 de marzo, en el que se establece que el Consejo de Gobierno cesa tras la celebración de elecciones al Parlamento y el Consejo de Gobierno cesante continuará en funciones hasta la toma de posesión del nuevo Consejo de Gobierno.

Por su parte la Ley 6/2006, de 24 de octubre, de Gobierno de Andalucía, en la misma línea que la normativa estatal y en similares términos expresa en su art. 37, lo siguiente:

1. El Consejo de Gobierno cesa cuando cesa la persona titular de la Presidencia de la Junta de Andalucía.

2. El Consejo de Gobierno cesante continuará en funciones hasta la toma de posesión del nuevo Consejo de Gobierno.

3. El Gobierno en funciones facilitará el normal desarrollo del proceso de formación del nuevo Consejo de Gobierno y el traspaso de poderes al mismo, limitándose su gestión al despacho ordinario de los asuntos públicos de su competencia, salvo casos de urgencia o interés general debidamente acreditados. 
4. El Presidente o la Presidenta en funciones de la Junta de Andalucía no podrá ser sometido o sometida a una moción de censura. Tampoco podrá ejercer las siguientes facultades:

a) Designar o separar a las personas titulares de las Vicepresidencias o de las Consejerías.

b) Crear, modificar o suprimir Vicepresidencias o Consejerías.

c) Disolver el Parlamento de Andalucía.

d) Plantear la cuestión de confianza.

5. El Consejo de Gobierno en funciones no podrá ejercer las siguientes facultades:

a) Aprobar el proyecto de Ley del Presupuesto de la Comunidad Autónoma.

b) Presentar proyectos de ley al Parlamento de Andalucía.

La interpretación de la normativa estatal en una primera aproximación se produjo por sentencia del Tribunal Supremo, de 20 de septiembre de 2005, que en su fundamento de derecho cuarto expresó: "Después del cese, la actividad gubernamental debe respetar una serie de restricciones. Aunque la Constitución no dice nada sobre sus posibles limitaciones, pues el art. 102.1 señala que "el Gobierno cesante continua en funciones hasta la toma de posesión del nuevo Gobierno", la práctica constitucional limitó su gestión a los asuntos de trámite.

Hoy, la Ley 50/1997, de 27 de noviembre, en su título IV, trata de las competencias que corresponden al Gobierno en funciones y en su art. 21, que desarrolla el art. 101 de la Constitución, se completa y establece, según el Diario de Sesiones del Congreso de los Diputados, una serie de requisitos y limitaciones, en el entendimiento de tener un tratamiento coherente de lo que es la fiducia quebrada entre las Cortes Generales y un Gobierno en funciones y la no pervivencia de determinados órganos de control que permitan establecer un control estable.

El número 3 del citado art. 21, de acuerdo con los principios establecidos en su exposición de motivos, precisa que "limitará su gestión al despacho ordinario de los asuntos, absteniéndose de adoptar, salvo caso de urgencia debidamente acreditados o por razones de interés general cuya acreditación expresa así lo justifique, cualesquiera otras medidas", teniendo en cuenta que, como dice la exposición de motivos, "el objetivo último de toda actuación 
radica en la consecución de un normal desarrollo del proceso de formación del nuevo Gobierno".

Es decir: la gestión administrativa ordinaria ausente de valoraciones y decisiones en las que entren criterios políticos salvo que se motive debidamente la urgencia o las razones de interés general que justifique la adopción de medidas de otra naturaleza."

En sentencia de 2 de diciembre de 2005 (recurso 161/2004), el Tribunal Supremo se pronunció de nuevo sobre la cuestión, perfilando su doctrina al respecto en los fundamentos de derecho Octavo y Noveno, concretamente en el fundamento octavo se indicaba:" La Constitución, ciertamente, no establece de modo expreso límites o restricciones a la actuación del Gobierno en funciones. No obstante, nos facilita el criterio para distinguir cuáles son los confines dentro de los que debe moverse, fuera de los casos en que la urgencia determine la necesidad de su intervención, pues la habilitación para resolver sobre estos últimos va implícita en la propia imposición de su existencia. El criterio al que nos referimos es el que resulta de la función constitucional del Gobierno. De la que ha de desempeñar el que está en plenitud de sus facultades tras haber completado el proceso de su formación. Esa función no es otra que la dirección de la política interior y exterior y, en estrecha relación con ella, la defensa del Estado. Esos son los cometidos con los que el artículo 97 de la Constitución singulariza la función gubernamental y para cuya realización atribuye al órgano Gobierno la dirección de la Administración Civil y Militar y le encomienda la función ejecutiva y la potestad reglamentaria.

La dirección de la política general, que es la misión principal del Gobierno, trae causa del programa que el candidato a su Presidencia defendió ante el Congreso de los Diputados y mereció el apoyo de su mayoría (artículo 99 de la Constitución). Programa que, a su vez, procede del que las fuerzas políticas que otorgaron su confianza al candidato a la Presidencia, presentaron ante los ciudadanos y logró el apoyo de sus votos. Naturalmente, ese marco político de actuación no queda definitivamente fijado en ese momento y puede suceder que, por distintas razones, el Gobierno llegue a apartarse en diversa medida de la línea aprobada en el momento de la investidura. El sistema parlamentario permite una actualización permanente de la relación de confianza a través de su normal desenvolvimiento o con el recurso a algunas instituciones previstas en la Constitución como el referéndum consultivo (artículo 92 ) o la cuestión de confianza ( artículo 112). En cualquier caso, mientras persista la relación de confianza entre el Congreso 
de los Diputados y, a través de su Presidente, el Gobierno, a este corresponde la dirección política de España. Así, gobernar para la Constitución, es dirigir el país a partir de las orientaciones definidas por el Presidente del Gobierno ( artículo 98.2 de la Constitución) con el apoyo de la mayoría parlamentaria formada democráticamente por los españoles.

Pues bien, si esto es lo que debe hacer el Gobierno que se forma, es, al mismo tiempo, lo que no puede hacer el Gobierno en funciones porque el cese ha interrumpido la relación de confianza que le habilita para ejercer tal dirección y le ha convertido en un órgano cuya composición debe variar necesariamente en el curso de un proceso constitucionalmente regulado, de una duración necesariamente limitada en el tiempo, del que surgirá una nueva relación de confianza y un nuevo Gobierno. Así, pues, el Gobierno en funciones ha de continuar ejerciendo sus tareas sin introducir nuevas directrices políticas ni, desde luego, condicionar, comprometer o impedir las que deba trazar el que lo sustituya. El cese priva a este Gobierno de la capacidad de dirección de la política interior y exterior a través de cualquiera de los actos válidos a ese fin, de manera que será preciso examinar, caso por caso, cuando surja controversia al respecto, si el discutido tiene o no esa idoneidad en función de la decisión de que se trate, de sus consecuencias y de las circunstancias en que se deba tomar".

En el fundamento de derecho noveno la sentencia referida afirma: "Con estos pertrechos interpretativos que encontramos en la Constitución hemos de examinar la Ley del Gobierno y asignar a la expresión despacho ordinario de los asuntos públicos de su artículo 21.3 un significado preciso en este caso, porque se trata de un concepto indeterminado necesitado de concreción. De cuanto acabamos de decir en el fundamento anterior se deduce que ese despacho no es el que no comporta valoraciones políticas o no implica ejercicio de la discrecionalidad. Tampoco el que versa sobre decisiones no legislativas, sino el que no se traduce en actos de orientación política.

De este modo entendida, o sea interpretada conforme a la Constitución, se despejan las dudas que pudiera ofrecer la conformidad con el texto constitucional de las normas legales que sujetan a límites la actuación del Gobierno en funciones cuando aquél no ha dispuesto expresamente ninguno. Por lo demás, situados en esta perspectiva, es posible apreciar que el mismo legislador asume esa interpretación porque en el apartado quinto del artículo 21 se preocupa por prohibir al Gobierno en funciones aprobar el proyecto de Ley de Presupuestos Generales del Estado (a) y presentar proyectos de Ley al Congreso de los Diputados o, en su caso, al Senado (b). Es decir, la Ley prohibe 
al Gobierno en funciones utilizar los principales instrumentos de orientación política, pues los Presupuestos Generales del Estado no son sino la traducción en términos de ingresos y gastos de la dirección política que el Gobierno quiere llevar a la práctica en el ejercicio de que se trate. Y las Leyes que, según el Preámbulo de la Constitución, son la expresión de la voluntad popular y proceden casi exclusivamente de la iniciativa gubernamental, introducen en el ordenamiento jurídico las normas que responden a las orientaciones que prevalecen en el electorado y, por tanto, en las Cortes Generales. Por eso, son uno de los cauces típicos de expresión de la orientación política decidida por el Gobierno y asumida por las Cortes Generales.

A parecidos resultados conduce, por lo demás, el apartado sexto de este artículo 21 de la Ley 50/1997, que deja en suspenso las delegaciones legislativas mientras el Gobierno esté en funciones por haberse celebrado elecciones generales. Además, este apartado es relevante porque introduce en la regulación legal una diferencia de régimen jurídico en atención a la causa determinante de la entrada en funciones del Gobierno. Circunstancia esta que refuerza las consideraciones antes realizadas sobre la necesidad de examinar caso por caso y asunto por asunto los que han de considerarse incluidos en el despacho ordinario y los que, por quedar fuera de él, no pueden ser abordados por el Gobierno en funciones de no existir urgencia o demandarlo el interés general contemplado en el artículo 21.3 de este texto legal. La aprobación del proyecto de Presupuestos Generales del Estado, el ejercicio de la iniciativa legislativa y la emanación de los decretos legislativos no son los únicos actos de orientación política prohibidos al Gobierno en funciones. La misma Ley 50/1997, en el apartado cuarto de su artículo 21, veda al Presidente en funciones proponer al Rey la disolución de una o de ambas cámaras de las Cortes Generales, presentar la cuestión de confianza o proponer al Rey la convocatoria de un referéndum consultivo, todos ellos actos de clara orientación política. Esto significa que la línea divisoria entre lo que el Gobierno en funciones puede y no puede hacer no pasa por la distinción entre actos legislativos y no legislativos, sino por la que hemos señalado entre actos que no conllevan dirección política y los que la expresan. Por tanto, la misma Ley 50/1997 responde a los criterios que, a juicio del Pleno de la Sala, presiden la concepción constitucional del Gobierno en funciones. Criterios que, por lo demás, se confirman viendo las cosas desde otra perspectiva. En efecto, asumir la tesis del recurrente supondría situar al Gobierno de España en una posición de precariedad tal que podría impedir o dificultar que ejerciera los cometidos que la Constitución le ordena realizar, pues en pocos actos gubernamentales están ausentes las motivaciones políticas o un margen de apreciación. 
En definitiva, el despacho ordinario de los asuntos públicos comprende todos aquellos cuya resolución no implique el establecimiento de nuevas orientaciones políticas ni signifique condicionamiento, compromiso o impedimento para las que deba fijar el nuevo Gobierno. Y esa cualidad que excluye a un asunto del despacho ordinario ha de apreciarse, caso por caso, atendiendo a su naturaleza, a las consecuencias de la decisión a adoptar y al concreto contexto en que deba producirse".

La anterior doctrina ha sido reiterada en la sentencia del Tribunal Supremo de 28 de mayo de 2013 (recurso de casación n. 231/2012), aunque en la misma se determinó que la aprobación del Gobierno en funciones de un Real Decreto, se puede situar en el ámbito del despacho ordinario de asuntos públicos, sin necesidad de concurrencia de situación de urgencia o interés general, si no conlleva orientaciones políticas o condiciones, comprometa o impida la acción del nuevo gobierno. Doctrina que debe extenderse a las disposiciones de carácter general, carácter del que participan los instrumentos de ordenación urbanística.

Se expresa en la demanda con acierto que el PPCLA fue aprobado por el Consejo de Gobierno en la sesión celebrada el día 26 de mayo de 2015, aunque fue publicado en el Boletín Oficial de la Junta de Andalucía de 20 de julio. En la fecha de su aprobación, el Gobierno de la Junta de Andalucía se hallaba en funciones, ya que el 22 de marzo anterior se habían celebrado elecciones autonómicas convocadas por Decreto 1/2015, de 26 de enero. La constitución del Parlamento de Andalucía no se produciría hasta el 16 de abril, la investidura de la Presidenta electa el 11 de junio, su toma de posesión el 14 de junio y la toma de posesión de los nuevos Consejeros el 18 de junio.

Sostiene la parte actora que el PPCLA constituye un ejercicio de la potestad normativa atribuida constitucional y estatutariamente al gobierno autonómico que implica de manera palmaria el establecimiento de una nueva orientación política, en la medida en que dicho plan se aparta consciente y públicamente de los planes de ordenación de ámbito subregional ya existentes y en vigor e incluso del Plan de Ordenación del Territorio de Andalucía, alterando radicalmente los objetivos y la finalidad de la política territorial en el ámbito del litoral andaluz y, consecuentemente, modificando de manera sustancial las directrices y determinaciones de dichos instrumentos, como un auténtico cambio de modelo. Esta nueva orientación política implica un condicionamiento, compromiso o Impedimento para la potestad de dirección política del nuevo Gobierno, desde el punto de vista estrictamente jurídico y objetivo, es decir, dejando al margen la consideración puramente fáctica y contingente de que el nuevo Gobierno está sustentado por el mismo 
partido político. En consecuencia, es forzoso concluir que la aprobación era una decisión que excedía del despacho ordinario de los asuntos públicos de competencia de un Gobierno en funciones.

El Tribunal Constitucional en sentencia 149/1991, de 4 de julio consideró que... "la ordenación del territorio es, efectivamente, más una política que una concreta técnica y una política, además, de enorme amplitud. La Carta Europea de Ordenación del Territorio, aprobada por la CEMAT (Conferencia Europea de Ministros de Ordenación del Territorio) el 23 de mayo de 1983, citada por muchos de los recurrentes la define como "expresión espacial de la política económica, social, cultural y ecológica de toda sociedad". Al hilo de la indicada doctrina no debe dudarse de que el PPCLA es un instrumento jurídico para la realización de la planificación territorial de Andalucía, tal y como establece el art. 5.1 de la Ley 1/1994, de 11 de enero de Ordenación Territorial. En la exposición de motivos de la misma se expresa que La Ordenación del Territorio constituye por tanto una función pública destinada a establecer una conformación física del territorio acorde con las necesidades de la sociedad. En este sentido, la Carta Europea de la Ordenación del Territorio la define como «expresión espacial de las políticas económica, social, cultural y ecológica de toda sociedad», y debe ser democrática, global, funcional y prospectiva, en la que todo ciudadano debe tener la posibilidad de participar por estructuras y procedimientos adecuados, en defensa de sus legítimos intereses y del respeto debido a su cultura y marco de vida.

La legislación o regulación específica por la que debe regirse la acción política y administrativa en esta materia es un hecho reciente, favorecido y posibilitado en España por la organización del Estado de las Autonomías.

Por tanto, el PPCLA como instrumento urbanístico de realización de la planificación del territorio, es la expresión espacial de la política económica, social, cultural y ecológica de la sociedad en el corredor litoral de Andalucía. Es perspicuo que el PPCLA asume la orientación política en general de ordenación del territorio, por ser un instrumento urbanístico previsto en la Ley 1/1994 y, especialmente, contiene sus propias directrices políticas de protección del corredor litoral.

Lo anterior se deduce claramente de la Introducción a la Memoria Informativa, en la que se indica: "el presente Plan de Protección del Corredor Litoral de Andalucía tiene como propósito desarrollar los contenidos que para el mismo establece la Ley 1/1994, de 11 de enero, de Ordenación del Territorio de Andalucía, modificada por el Decreto- Ley, de 27 de noviembre, 
de medidas urgentes en materia urbanística y para la protección del litoral de Andalucía... En este marco, el Plan de Protección del Corredor Litoral centra su atención en la franja costera, el espacio más tensionado del litoral, al objeto de establecer un tratamiento integrado que permita compatibilizar el desarrollo de un ámbito que se considera esencial para nuestro sistema productivo, con su sostenibilidad económica y ambiental”.

A mayor abundamiento, en la Memoria de Ordenación en el apartado 1. Objetivos se consideran como tales objetivos generales ... "el establecimiento de criterios y determinaciones para la protección, conservación y puesta en valor de las zonas costeras andaluzas desde objetivos de perdurabilidad y sostenibilidad. El corredor litoral se estima como recurso de interés general, en el que es necesario compatibilizar la protección y preservación de la urbanización de los espacios libres de edificación con el desarrollo sostenible de los espacios costeros, de forma que se garantice la calidad de vida de las generaciones presentes y futuras. Se entiende que el litoral de Andalucía es un territorio de oportunidades. Sus características físico-territoriales, sus valores ambientales y sus condiciones climáticas han sido los elementos en los que se ha sustentado en las últimas décadas un importante desarrollo basado fundamentalmente en la agricultura y el turismo. Se expresa que la acción llevada a cabo en los último años desde la administración autonómica mediante las políticas de protección ambiental y de ordenación territorial ha permitido preservar espacios y establecer modelos de crecimiento apropiados a las características de cada uno de los tramos litorales, proponiendo acciones positivas de adecuación y acondicionamiento para usos urbano-turísticos, favoreciendo el uso público, reforzando modelos urbanos de desarrollo compacto, propiciando la protección de determinadas áreas agrícolas, etc.. En el momento actual se precisa de una más decidida actuación de protección del litoral, al menos en su franja costera más sometida a las presiones urbanísticas, porque es sobre esta franja donde se sustenta todo el desarrollo económico del litoral, en la que la degradación paisajística ha alcanzado mayores cotas y en la que los valores ecológicos y ambientales están sometidos a una mayor presión".

En la línea del indicado propósito general, se establecen como objetivos específicos los siguientes:

1. Preservar de la urbanización las zonas con valores ambientales, naturales, paisajísticos, culturales, agrícolas y forestales de los espacios litorales.

2. Evitar la consolidación de nuevas barreras urbanas entre los espacios interiores y los del sistema litoral. 
3. Armonizar la regulación del suelo no urbanizable en el ámbito del Plan.

4. Favorecer la biodiversidad a través de continuidad de los espacios del interior con el litoral.

5. Propiciar el mantenimiento del litoral como recurso turístico básico evitando su consolidación con nuevos usos residenciales estacionales.

El desarrollo de estos objetivos se lleva a cabo a través de actuaciones de consecuencias urbanísticas, patrimoniales y ambientales:

Urbanísticas, cuya finalidad es evitar al consolidación de un continuo edificado que podría llegar a cubrir una parte sustancial de la línea de costas y armonizar la regulación de suelo no urbanizable estableciendo los criterios y directrices para su preservación.

Patrimoniales, cuyo objeto es preservar los espacios costeros por sus valores paisajísticos, naturales y culturales.

Ambientales, cuyo fin es posibilitar la preservación del medio costero y asegurar la continuidad entre los ecosistemas terrestres y marítimos.

Lo extractado y expuesto en el fundamento de derecho anterior, reafirma lo que se expresaba en el fundamento de derecho octavo in fine de la presente sentencia, en cuanto a que el PPCLA asume la orientación política en general de ordenación del territorio, y especialmente, en la medida en que su normativa contiene sus propias directrices políticas para regular la actividad de gobierno de protección del corredor litoral andaluz.

Por tanto, es forzoso concluir en consonancia con la doctrina del Tribunal Supremo más arriba expuesta, que el Decreto 141/2015, de 26 de mayo, de aprobación definitiva del Plan de Protección del Corredor Litoral de Andalucía, no puede considerarse despacho ordinario de asuntos públicos, debido a que por su clara y meridiana orientación política y su vocación y proyección de futuro, excede del indicado concepto y condiciona y compromete al nuevo Gobierno, con independencia de que el nuevo Gobierno, estuviese sustentado por el mismo partido político. No debe olvidarse, que la exposición de motivos de la Ley 50/1997, del Gobierno, destaca que el Título IV se dedica exclusivamente a regular el gobierno en funciones, una de las principales novedades de la ley, con base en el principio de lealtad constitucional, delimitando su propia posición constitucional y entendiendo que el objetivo último de su actuación radica en la consecución de un normal desarrollo del proceso de formación del nuevo Gobierno. 
Efectivamente es el indicado principio de lealtad constitucional, el que limita los actos del Gobierno en funciones al despacho ordinario de los asuntos públicos y al mismo tiempo, el que prohibe la aprobación de actos que supongan el establecimiento de orientaciones políticas, para no comprometer ni condicionar al nuevo Gobierno, sea o no del mismo partido político, pues ni la ley estatal ni la autonómica establecen ningún tipo de distinción al respecto.

La concluida orientación política de la aprobación del PPCLA, no puede quedar eliminada por la alegación contenida en el escrito de contestación a la demanda, referente a que la formulación y aprobación del plan, viene impuesta por el legislador, en concreto por la Ley 1/1994, de 11 de enero. Como se expuso con anterioridad, el PPCLA como instrumento urbanístico de realización de la planificación del territorio, es la expresión espacial de la política económica, social, cultural y ecológica de la sociedad en el corredor litoral de Andalucía. Es evidente que el PPCLA asume la orientación política en general de ordenación del territorio, por ser un instrumento urbanístico previsto en la Ley 1/1994 y, especialmente, contiene directrices políticas de protección del corredor litoral. Por tanto la previsión en la Ley 1/1994 de la aprobación y formulación del PPCLA, obedece a la ordenación del territorio, de cuyo desarrollo es fiel reflejo el PPCLA, que en su propia orientación política es autónomo, por lo que la referida previsión en la Ley 1/1994, lejos de enervar las orientaciones políticas, lo que hace es reafirmarlas.

No debe dejarse de advertir que el acto de aprobación definitiva del PPCLA, realizado por el Gobierno en funciones, atendía a la validez del mismo en la fecha en que se produjo -26 de mayo de 2015- con independencia de que la publicación se produjese en el BOJA de 20 de julio, acto de publicación referido a la eficacia del plan, como expresan las sentencias del Tribunal Supremo de 12 de noviembre de 2010 y de 18 de noviembre de 2011 . Por tanto, la aprobación definitiva del pian, fuese o no válida, que es lo que se trata de enjuiciar en la presente sentencia, la realizó el Gobierno en funciones, con independencia de la publicación realizada por el nuevo Gobierno atinente a la eficacia del acto.

Aunque el Decreto 141/2015, de 26 de mayo, cuyo contenido integro se recoge en el fundamento de derecho cuarto de la presente sentencia, no hace la más mínima mención a razones de urgencia o de interés general, que justificadas en su caso, ampararían la aprobación definitiva del PPCLA, pese a su contenido político, debe hacerse referencia a la existencia de un informe de 25 de mayo de 2015 (DVD 1, Carpeta 8, folios 2418-2420), de 
la Secretaría General de Ordenación del Territorio y Cambio Climático, en el que se aducen razones de urgencia e interés general, que ponen de manifiesto el convencimiento de la Administración del carácter político de la aprobación definitiva del PPCLA.

En su apartado III. Sobre la Necesidad de Aprobación del Plan por el Consejo de Gobierno, se expresa: Por Decreto de la Presidenta 1/2015, de 26 de enero, se acordó la disolución del Parlamento de Andalucía y la convocatoria de elecciones, razón por la cual el Consejo de Gobierno se encuentra desde esa fecha en funciones, con las limitaciones que para la adopción de acuerdos se establecen en el art. 37 de la Ley 6/2006, de 24 de octubre, del Gobierno de la Comunidad Autónoma de Andalucía, que limita su gestión al despacho ordinario de los asuntos públicos de su competencia, salvo casos de urgencia o interés general debidamente acreditados.

Por todo lo expuesto, desde esta Secretaría General se propone elevar al Consejo de Gobierno la aprobación del Plan de Protección del Corredor Litoral de Andalucía, en razón a las siguientes consideraciones:

1) La elaboración del Plan se ha llevado a cabo conforme a los trámites preceptivos establecidos en las normas de aplicación y se encuentra actualmente ultimada, pendiente exclusivamente del acto de aprobación por el Consejo de Gobierno, todo ello en el plazo de dos años y seis meses legalmente establecido.

2) Razones de urgencia justifican la aprobación antes del 27 de mayo de 2015, fecha límite del plazo fijado, ya que de otro modo se estaría incumpliendo una disposición legal con las consecuencias jurídicas que de ello pudieran derivarse respecto de la nulidad del Plan en un posible recurso contencioso administrativo.

3) De otra parte, la no aprobación del Plan en el plazo fijado motivaría el levantamiento de la suspensión cautelar establecida por el Decreto Ley 5/2012, de 27 de noviembre, respecto de la aprobación de instrumentos de planeamiento de desarrollo en zonas protegidas por el nuevo instrumento, lo que incrementaría los gastos derivados de posibles indemnizaciones en el caso de aprobarse el Plan con posterioridad, en los siguientes supuestos:

Sectores de suelo urbanizable sin Plan Parcial aprobado que podrían iniciar su tramitación, con un total de 46 sectores (30 sectorizados y 16 no sectorizados), una superficie aproximada de 2000 hectáreas con capacidad para unas 31.000 viviendas. 
Sectores de suelo urbanizable con Plan Parcial aprobado, a los que si bien no les afecta la suspensión, podrían iniciar materialmente su ejecución. Esto sería el caso de los Planes Parciales de Valdevaqueros y Los Lances en Tarifa y El Cañar y el Camillar en Carboneras, próximos al El Algarrobico, ubicados todos en zonas de gran valor ambiental.

4) En definitiva, la no aprobación del Plan de Protección del Corredor Litoral de Andalucía, en el plazo legalmente establecido dejaría sin efecto el objeto de salvaguardar intereses generales sujetos a la tutela de la Comunidad Autónoma presentes en este ámbito, ya que impediría la protección y puesta en valor de la franja costera e imposibilitaría un desarrollo urbanístico sostenible adecuado a la capacidad de acogida del territorio.

Interesa destacar que la motivación de los actos y resoluciones administrativas por remisión a informes y dictámenes estaba contemplada en el art.89.5 de la Ley 30/1992, de 26 de noviembre, exigiéndose a la aceptación de informes o dictámenes para servir de motivación a la resolución la incorporación de aquellos al texto de la misma. Ciertamente como a continuación se expondrá la doctrina del Tribunal Supremo, ha establecido matices en la denominada motivación in alliunde. No obstante, el legislador, mantiene idéntica exigencia en cuanto a la motivación por remisión, en el art. 88.6 de la actual Ley 39/2015, de 1 de octubre.

La denominada motivación in alliunde o per relationem ha sido tratada por el Tribunal Supremo .entre otras, en sentencia de 15 de enero de 2009 (Rec. Conté. 329/2005 ), en la que se expresó:” La motivación de los actos administrativos, según reiterada doctrina del Tribunal Constitucional y jurisprudencia de este Tribunal Supremo cuya reiteración excusa cita, cumple una doble finalidad, de un lado, da a conocer al destinatario de los mismos las razones, concretas y precisas aunque no exhaustivas, de la decisión administrativa adoptada, para que con tal conocimiento, la parte pueda impugnarla ante los órganos jurisdiccionales, y estos, a su vez -esta es la segunda finalidad-, puedan cumplir la función que constitucionalmente tienen encomendada de control de la actividad administrativa y del sometimiento de ésta a los fines que la justifican, ex artículo 106.1 CE.

El cumplimiento de esta exigencia de la motivación de los actos, con sucinta referencia a los hechos y fundamentos en que se basa, previsto en el artículo 54 de la Ley 30/1992, se salvaguarda mediante la severa consecuencia de la anulabilidad del acto administrativo no motivado, en caso de incumplimiento. Ahora bien, esta ausencia de motivación puede ser un vicio invalidante, como hemos señalado, o de mera irregularidad en el caso de 
que no se haya producido ese desconocimiento de los motivos y razones en que se funda la decisión administrativa. Dicho de otra forma, debe atenderse a un criterio material en orden a determinar si efectivamente se ha cumplido, o no, la finalidad que exige la motivación de los actos, es decir, si el destinatario ha llegado a conocer las razones de la decisión adoptada por la Administración, pues solo si se conocen pueden impugnarse. Se trata, en definitiva, de valorar si concurre la indefensión a que se refiere el artículo 63.2 de la Ley 30/1992 cuya existencia es necesaria para incurrir en el vicio de invalidez señalado. El defecto de forma "solo determinará la anulabilidad cuando el acto carezca de los requisitos formales indispensables para alcanzar su fin o de lugar a la indefensión de los interesados", nos indica el citado artículo 63.2.

En este sentido, la motivación puede contenerse en el propio acto, o bien puede realizarse por referencia a informes o dictámenes, ex artículo 89.5 de la Ley 30/1992, cuando se incorporen al texto de la misma. Ahora bien, esta exigencia de la incorporación de los informes, contenida en el mentado artículo 89.5 "in fine", ha sido matizada por la jurisprudencia de este Tribunal Supremo -Sentencias de 21 de noviembre de 2005,12 de julio de 2004,7 de julio de 2003,16 de abril de 2001,14 de marzo de 2000 y 31 de julio de 1990 - en el sentido de considerar que si tales informes constan en el expediente administrativo y el destinatario ha tenido cumplido acceso al mismo, la motivación mediante esta técnica "in aliunde" satisface las exigencias de la motivación, pues permite el conocimiento por el receptor del acto de la justificación de lo decidido por la Administración”.

Por su parte la sentencia del Tribunal Supremo, de 15 de febrero de 2014, indica lo siguiente: "Así pues, la sentencia cuestionada no incurre en el defecto de motivación que se le imputa por la sociedad recurrente, teniendo en cuenta que, dentro de las modalidades que puede revestir la motivación, cabe la motivación por remisión, que es lo que realizó adecuadamente la Sala de instancia. Sobre ello conviene recordar que dentro de las modalidades que puede revestir la motivación está la que se realiza por remisión o in aliunde, técnica en virtud de la cual se incorporan a la resolución los razonamientos jurídicos de la decisión o documento a la que se remite (ATC 207/1999, de 28 de julio, FJ 2).

Esta técnica de motivación "no deja de serlo ni de satisfacer la exigencia constitucional contenida en el derecho fundamental a la tutela judicial efectiva", como explican, entre otras muchas, las SSTC núm. 187/2000, de 10 de julio, FJ 2; la núm. 8/2001, de 15 de enero, FJ 3, in fine; la 13/2001, 
de 29 de enero (RTC 2001 ,13), FJ 2; la 108/2001, de 23 de abril, FJ 2; la 5/2002, de 14 de enero, FJ 2; la 171/2002, de 30 de septiembre, FJ 2; y ATC 194/2004, de 26 de mayo, FJ 4 b).

Ahora bien, esta forma de motivación será válida siempre y cuando dicha remisión se produzca de forma expresa e inequívoca ( STC núm. 115/1996, de 25 de junio FJ 2. b) y siempre que la cuestión sustancial de que se trate se hubiera resuelto en la resolución o documento al que la resolución judicial se remite (SSTC 27/1992, de 9 de marzo, FJ 4, y 202/2004, de 15 de noviembre, FJ 5; y ATG 312/1996, de 29 de octubre, FJ 6).

Sobre esta cuestión también es pacífica la doctrina de esta Sala, valiendo como exponentes las sentencias de 25 de junio de 2012 (rec. cas. núm. $5160 / 2010$ ) o la de 5 de diciembre de 2011 (rec. cas. 2523/2010), exponiendo la primera que "con este reenvío se da a este primer motivo de casación una respuesta adecuada a las exigencias inherentes a la tutela judicial efectiva proclamada en el artículo 24.1 de la Constitución española, porque este derecho fundamental se satisface con la motivación por remisión o aliunde, siempre que el reenvío se produzca de forma expresa e inequívoca y la cuestión sustancial de que se trate hubiera sido decidida en la resolución a que se remite, según ha reiterado el Tribunal Constitucional en la sentencia 144/2007 (FJ 30):

"Dentro de las modalidades que puede revestir la motivación hemos afirmado que la fundamentación por remisión o in aliunde - técnica en virtud de la cual se incorporan a la resolución que prevé la remisión los razonamientos jurídicos de la decisión o documento a la que se remite (ATC 207/1999, de 28 de julio, FJ 2)-"no deja de serlo ni de satisfacer la exigencia constitucional contenida en el derecho fundamental" a la tutela judicial efectiva (entre otras muchas, SSTC 187/2000, de 10 de julio, FJ 2; 8/2001, de 15 de enero, FJ 3, in fine; 13/2001, de 29 de enero, FJ 2; 108/2001, de 23 de abril, FJ 2; 5/2002, de 14 de enero, FJ 2; 171 /2002, de 30 de septiembre, FJ 2; y ATC 194/2004, de 26 de mayo, FJ 4 b); en términos similares, SSTC 115/2003, de 16 de junio, FJ 8; 91 /2004, de 19 de mayo, FJ 8; 113/2004, de 12 de julio, FJ 10; 75/2005, de 4 de abril, FJ 5 ; y 196/2005, de 18 de julio , FJ 3), siempre y cuando dicha remisión se produzca de forma expresa e inequívoca [STC 115/1996, de 25 de junio, FJ 2 b)] y que la cuestión sustancial de que se trate se hubiera resuelto en la resolución o documento al que la resolución judicial se remite (SSTC 27/1992, de 9 de marzo, FJ 4; y 202/2004, de 15 de noviembre, FJ 5; y ATC 312/1996, de 29 de octubre, FJ 6)" (FD Segundo)". 
Expuesta la doctrina del Tribunal Supremo, debe reiterarse que, como ya hemos señalado en precedente fundamento, el Decreto 141/2015, de 26 de mayo de aprobación del PPCLA, no menciona ni justifica razón alguna de urgencia o de interés general que motivaran la aprobación por el Gobierno en Funciones, tal y como exige el art. 37 de la Ley 6/2006. No sólo no justifica la aprobación en las indicadas razones, sino que ni tan siquiera menciona, remite o reenvía al contenido del informe de 25 de mayo de 2015, de la Secretaria General de Ordenación del Territorio y Cambio Climático.

A mayor abundamiento las razones de urgencia y de interés general que contiene el mentado informe de 25 de mayo de 2015, recogidas en el fundamento de derecho undécimo de la presente sentencia, no se sostienen jurídicamente.

No puede justificarse como razón de urgencia la aprobación antes del 27 de mayo de 2015, fecha límite del plazo fijado (2 años y 6 meses), ya que de otro modo se estaría incumpliendo una disposición legal con las consecuencias jurídicas que de ello pudieran derivarse respecto de la nulidad del Plan en un posible recurso contencioso administrativo.

Al respecto debe recordarse la doctrina del Tribunal Supremo atinente a que la institución de la caducidad del procedimiento administrativo no es aplicable a los instrumentos de ordenación que participan de la naturaleza de disposiciones de carácter general, contenida ,entre otras, en la sentencia de 8 de marzo de 2012 (recurso de casación 2305/2008), que declaró haber lugar al recurso de casación interpuesto por la dirección jurídica de la Junta de Andalucía, contra sentencia de esta Sala y Sección de 6 de marzo de 2008, que estimo el recurso contencioso administrativo y declaró la nulidad del Decreto 130/2006, de 27 de junio, en la que se afirma lo que sigue:

"La sentencia impugnada concluye en su fundamento tercero, que antes transcribimos, que el plazo de un año para «la elaboración» del Plan de ordenación territorial del sector occidental de Huelva, establecido en el Decreto del Consejo de Gobierno de la Junta de Andalucía 52/1999, de 2 de marzo, de incoación del expediente, tiene una naturaleza « esencial». También que, al haberse aprobado definitivamente el Plan territorial en cuestión el día 27 de junio de 2006, se infringió el citado plazo. Y, en definitiva, que responde a « el mismo fundamento y naturaleza que la caducidad» con la única peculiaridad del«mecanismo en su establecimiento, en tanto que no lo impone directamente la ley, sino el Acuerdo de inicio del expediente». Y anula así el Plan por haberse aprobado en un procedimiento que había caducado. Conclusión de la sentencia que vino a aceptar lo alegado 
al respecto por el Ayuntamiento de Punta Umbría en su demanda sobre la aplicación de caducidad al procedimiento administrativo en cuestión conforme a lo dispuesto en el artículo 44.2 de la Ley 30/1992, de 26 de noviembre.

Tal y como alega la Junta de Andalucía en este motivo de casación, esas conclusiones de la sentencia no son correctas.

La doctrina especializada y la jurisprudencia constante de esta Sala viene considerando que los instrumentos de ordenación territorial y urbanística ostentan la naturaleza de disposiciones de carácter general porque tras su aprobación se incorporan al ordenamiento jurídico, su vigencia y fuerza vinculante permanece de manera indefinida en el tiempo y se consolidan en cada acto de aplicación. También por su específica configuración legal, que expresamente les atribuye los principios de inderogabilidad singular, publicidad y jerarquía normativa, característicos de las disposiciones reglamentarias (artículos 51 y 52 de la Ley 30/1992, de 26 de noviembre). Por todas, sentencia de esta Sala de 11 de diciembre de 2009 (Casación 5100/2005).

La institución de la caducidad del procedimiento administrativo ( artículos 43.4 y 92 de la Ley 30/1992, de 26 de noviembre en su versión original, o artículo 44.2 tras su reforma por Ley 4/1999, de 13 de enero ) se circunscribe a los procedimientos de producción de actos o resoluciones administrativas, no a los de aprobación de disposiciones de carácter general (Sentencias del Tribunal Supremo de( Sentencias del Tribunal Supremo de 13 de octubre de 2011 (Casación 3214/2008) y de 17 de noviembre de 2010 (Casación 1473 / 2006). Por esa razón y conforme a la legislación sectorial de la ordenación territorial y urbanística, los efectos que genera la demora o inactividad de la Administración en la tramitación de un instrumento de ordenación no son los de la caducidad del procedimiento, sino los del silencio administrativo positivo o negativo según los casos.

Esta conclusión se refuerza si se considera la finalidad a la que responde el referido plazo de un año fijado en el Decreto de incoación del expediente, que no es otra que la de apremiar a los distintos órganos responsables de la elaboración del Plan de Ordenación del Territorio, para que, con su rápida aprobación, los intereses públicos a los que da cobertura dicho Plan se vean satisfechos con prontitud. La anulación del Plan por la mera superación de ese plazo produciría precisamente el resultado contrario al que se pretendió con la fijación del plazo, generando un retraso aún mayor en la satisfacción de esos intereses públicos, lo que no dejaría de ser un absurdo [(Sentencias 
del Tribunal Supremo de 16 de noviembre de 1992 (Casación 1018/1987) de 14 de octubre de 1996 (Apelación 151 /1991) y de 27 de marzo de 1998 Casación 137/1995)].

Por otra parte, se alcanzaría también idéntica conclusión -falta de caducidad del procedimiento en que se aprobó el Plan de Ordenación del Territorio del Litoral Occidental de Huelva- si se tiene en cuenta que atendiendo a la fecha de incoación del expediente (2 de marzo de 1999), aún en la hipótesis de que no se tratase de una disposición de carácter general, tampoco se le podría aplicar el régimen de la caducidad, por cuanto el artículo 43.4 de la Ley 30/1992, de 26 de noviembre (en su versión original aplicable al caso, anterior a la Ley 4/1999), sólo se refería a los expedientes« no susceptibles de producir actos favorables para los ciudadanos», como los sancionadores [ sentencia del Tribunal Supremo de 30 de septiembre de 2011 (Casación 2377/2008) entre otras muchas]. En ningún caso se aplicaría a los instrumentos de ordenación del territorio, que se dirigen precisamente a producir efectos favorables para el bienestar de los ciudadanos.

En consecuencia, la sentencia impugnada podía en su caso haber anulado el Plan Territorial en cuestión por infringir alguna norma concreta reguladora del contenido de sus distintos documentos, o los límites de la potestad discrecional de planeamiento, si comprobase la concurrencia de defectos y discordancias esenciales con la realidad que pretende ordenar. Pero lo que no podía hacer es -como sin embargo hizo- anularlo por el mero transcurso del plazo de un año establecido en la resolución de incoación del expediente para la elaboración del plan, porque dicho plazo no constituye un término de caducidad del procedimiento. A mayor abundamiento, el mentado plazo de un año, se circunscribía en sus estrictos términos a la «elaboración» del proyecto del Plan, no a su aprobación definitiva. Y, en fin, el plazo se fija por el mismo órgano al que le corresponde la aprobación definitiva del Plan, disponiendo por ello de la posibilidad de apreciar, en el momento de dicha aprobación definitiva, si por el transcurso de ese término se han alterado o no en tal manera los presupuestos de partida hasta el punto de que el Plan proyectado haya perdido su objeto y carezca de sentido aprobarlo, lo que no ha ocurrido en el presente caso, sino al contrario".

Tampoco puede encontrarse razón de urgencia que se intenta justificar en que la no aprobación en el indicado plazo, determinaría el levantamiento de la suspensión de los planes de sectorización y de los planes parciales, que según el art. 2.3 del Decreto Ley, tenía una vigencia máxima de dos años y seis meses, pues como acertadamente se apunta en la demanda, obviamente 
en 15 días no era posible esperar un aluvión de aprobación de planes, de ahí, que era perfectamente posible y razonable esperar la constitución y posesión del nuevo Gobierno para la aprobación definitiva, sin que se acierte a comprender que ese mínimo retraso perjudicase la satisfacción de los intereses generales determinados y concretados en la protección del litoral.

En base a lo anteriormente expuesto procede la estimación del recurso, por falta de competencia del Gobierno en funciones para la aprobación del PPCLA, lo que conlleva la nulidad de pleno derecho del Decreto 141/2015, de 26 de mayo, de conformidad con lo dispuesto en el art. 62.1b) de la Ley 30/1992, de 26 de noviembre, entonces vigente.

Procede la condena en costas de la Administración demandada, al haber sido desestimada su pretensión, sin que pueda exigirse por todos los conceptos, mayor cantidad de 800 euros, dada la concurrencia de diversos recursos con idéntico objeto.

Vistos los artículos citados y demás de general y pertinente aplicación,

\section{FALLAMOS}

Estimado el recurso contencioso administrativo interpuesto por la Sra. Procuradora Da. María Elisa Sillero Fernández en nombre y representación de la la entidad mercantil SAL, S.A, debemos declarar y declaramos nula de pleno de derecho la disposición impugnada, con expresa condena en costas a la Administración recurrida con el límite establecido en el fundamento de derecho decimotercero de esta resolución.

(St. de 11 de octubre de 2017. Sala de Sevilla. Ponente Ma Rosa López Velasco) 